Int. J. Dev. Biol. 58: 51-56 (2014)

doi: $10.1387 / \mathrm{ijdb} .140013 \mathrm{hn}$

\title{
Xenopus cadherin 5 is specifically expressed in endothelial cells of the developing vascular system
}

\author{
HERBERT NEUHAUS*, SANJEEVA METIKALA and THOMAS HOLLEMANN \\ Martin-Luther-University Halle-Wittenberg, Institute for Physiological Chemistry, Halle (Saale), Germany
}

\begin{abstract}
Vasculogenesis is an important, multistep process leading to the formation of a functional primary network of blood vessels in the developing embryo. A series of interactions between secreted growth factors and their specific receptors leads to the specification of mesodermal cells to become hemangioblasts, which then differentiate into angioblasts. These subsequently proliferate, coalesce into cords and finally form tubular vascular structures. For proper function of these primary blood vessels, the close connection of endothelial cells is required. This is conferred by the interaction of an endothelium specific cadherin (Cadherin-5), starting during early vascular development. However, this interaction remains important throughout life and ageing. Therefore, cadherin-5 is a useful marker for late stages of vasculogenesis in several vertebrate species. To establish cadherin-5 as a marker for vascular studies in Xenopus, we cloned the Xenopus laevis ortholog and analyzed its expression pattern during embryogenesis.
\end{abstract}

KEY WORDS: vasculogenesis, cadherin, early embryogenesis, ageing, paralogs

\section{Identification and cloning of the Xenopus laevis cadherin-5 ortholog}

The cardiovascular system is the first organ system whose function is required for efficient exchange of nutrients, gases and waste products and in consequence for continuous growth of a developing embryo (Risau, 1995). A primary vascular network is established by the process of vasculogenesis (Pardanaud et al., 1996). In a first step mesodermal cells differentiate into precursors of the endothelial and blood cell lineage (hemangioblasts) short after gastrulation (Turpen et al., 1997). Commited angioblasts proliferate as a response to VEGF signals from regions adjacent to the mesoderm. VEGF ligand binds to three tyrosine kinase receptors, VEGFR-1 (FLT-1), VEGFR-2 (Flk-1/KDR) and VEGFR-3 (Flt-4) (Holmes et al., 2007) (Dumont et al., 1995) (Cleaver et al., 1997). Flt-1 and Flk-1 both bind VEGF-a and functional studies demonstrated that they are required for vasculogenesis during embryonic development, probably due to the activity of Etv2, an ETS-protein related transcription factor (Flamme et al., 1995) (Fong et al., 1995) (Neuhaus et al., 2010) (Salanga et al., 2010). Corresponding to their expression in vascular endothelial cells, Flt-1 and Flk-1 are the earliest known endothelial marker genes (Breier et al., 1996) (Fong et al., 1995). Subsequent to their proliferation the angioblasts coalesce into continuous cords. The formation of open spaces between two cells of these endothelial cords starts the development of endothelial vascular tubes (Houser et al., 1961). Cells forming these tubular structures now express junctional proteins as vascular-endothelial cadherin (cadherin-5, cdh5, CD144), which is frequently used as a marker for advanced stages of vasculogenesis and angiogenesis (Breier et al., 1996). However, in mice cdh5 expression and flk-1 expression were both detected by in situ hybridization in mesodermal cells of the yolk sac mesenchyme forming the first blood islands already at embryonic day 7.5 (Breier et al., 1996; Yamaguchi et al., 1993). Mouse embryos carrying a homozygous null mutation of $V E$ cadherin showed severe vasculogenic defects in the yolk sac and the embryo. From E9.5 those embryos were abnormal and died at E11.5 (Gory-Faure et al., 1999). In zebrafish embryos cdh5 expression is already detectable in anterior and trunk mesodermal cells at $12 \mathrm{hpf}$ before formation of vessel primordia (Larson et al., 2004). A knockdown of VE-cadherin in zebrafish did not affect vascular development and vessel sprouting, but cardiac looping and circulation were impaired. Additionally, the separation of the myocardial and endocardial layer were abnormal (Mitchell et al., 2010). To establish cdh5 as a marker for the analysis of blood vessel development in the frog we cloned the cdh5 ortholog from

Abbreviations used in this paper: VEGF, vascular endothelial growth factor.

\footnotetext{
*Address correspondence to: Herbert Neuhaus. Martin-Luther-University Halle-Wittenberg, Institute for Physiological Chemistry, 06114 Halle (Saale), Germany. Tel: +49-345-557-3829. Fax: +49-345-557-3812. e-mail: herbert.neuhaus@ medizin.uni-halle.de web: http://www1.medizin.uni-halle.de/ag-hollemann/hollemannhome.html
}

Accepted: 13 February 2014. Final, author-corrected PDF published online: 30 April 2014.

ISSN: Online 1696-3547, Print 0214-6282 
$\begin{array}{cllll}\mathrm{X} 1 & 1 & M K V Q R L Q F L M I M C C S L P L L L F S K E I T N S E S Y P A K N S R R V K R G W I W N Q M F I Q E E Q P G N L P H & 60 \\ \mathrm{Xt} & 1 & \text { M--KW----I----...------E--A-TH-D-TT------------S--RN----- } & 58\end{array}$

X1 50 YVGKLQINSSNVHENAKFAIQGESANTIFKVNERNGDIYCFERLDREKKIEYHLMALLVD 120

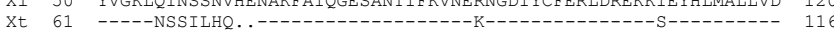

XI 110 KRTNKTLEHPSNEI IKVLDINDNAPEFTQKAFNGSVNEMSDRGIFVTKVNAVDKDDPTIG 180

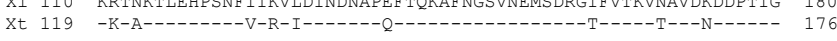

XI 170 GNADVNYRIIQGQEYFTIDNNGAIYTAVPNLDREQKDTYEVLVEARDSPGRTLYLASTAI 240

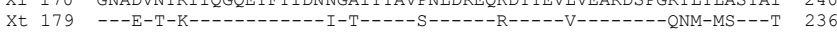
XI 230 VTIRLIDINDNFPTFTEREFKFNVPETGSWGRS.GRLKVEDIDEPQNRNTKYSFLKERFQ 299

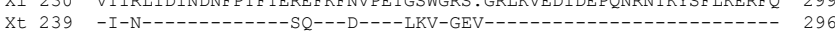

XI 289 EMFAVTTNAITNEGILILKKPLDYESVKQYKMDIEATDPLIDLRVARQPRPKSITNVIIN 359

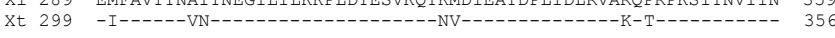
$\begin{array}{lrll}\text { XI } & 349 & \text { VLDVDEPPVFSKPFYKFEISENSKLTNIIGFVSAKDPDAANRNIRYSMRNFKDEPIKVTS } & 419 \\ \text { Xt } & 359 & -\end{array}$

XI 409 TGNIINVKTLDRETADWHNFTVVAEEVDPSNPPIKKESLGLVFIKVLDVNDNAPEFAEHY 479 Xt $419 \mathrm{~N}-1-0$

XI 469 APRVCENAAHQTVIANISATDKDEMKPGTKFTYYSAKKENNETVQDNHDNTATILVKYGY 539 Xt 479 -

XI 529 FNREVAKFHYLPIVISDNGQPEQSSTNTLTITVCKCNEKGEFTFCEEPA. KLAAVSVPTI 598 Xt 539 -

XI 588 IIILVSLFLIILVVAILAVLRRMQKKDTNILGKNTAEIHEQLVTYDEEGGGEMDTNSYDV 658 Xt 598 V--F--

X1 635 SVLNSVRRNVQRPRQDMETDPYLYAHVQKPARNGDMSFMIEVKKDEADNNGEGLPYDTLH 718

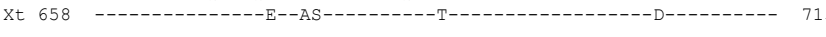
XI 635 IFGYEGSESIVESLSSIESGSSESDIDYDVLNNWGPRFKMLAELYGLEPIGDFPY 773

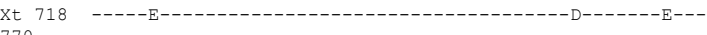

$88,6 \div$ Identity
Fig. 1. Sequence alignements of vertebrate CDH5 proteins. (A) Comparison of the putative amino acid sequence of the newly cloned cdh5 cDNA from Xenopus laevis with the cdh5 amino acid sequences from Xenopus tropicalis demonstrates that cdh5 is well conserved between the two frog species, sharing 89\% identity to each other. (B) Comparison of the deduced cdh5 amino acid sequences from Xenopus laevis (Xla; GenBank Accession no. KF279630), Homo sapiens (Hsa; GenBank Accession no. NP_001786), Mus musculus (Mmu; GenBank Accession no. AAH54790), Gallus gallus (Gga; GenBank Accession no. AAN33002), Danio rerio (Dre; GenBank Accession no. AY496430). The N-terminal signal peptide is boxed in red, the five typical extracellular Ca2+-binding Cadherin repeats are boxed in yellow, the transmembrane region is boxed in blue and the intracellular, catenin binding domain is boxed in green. Percentage identities are indicated at the end of the aligned sequences.

B Signal peptide

EC1

........ DKTTRRVKRGWIWNQMFISEER. NGNLPHYVGKLNSSILHQNAKFAIQGESANTIFKVNEKNGDIYCFER 88 Hsa 1 MQRLMMLLATSGACLG--AVAAVAAGAN......PAQRDTHSLLP-HR-Q--D------H-D--K.-TS---H---IK--VSRK---YLLK--YVGKV-R-DAET--VFAI-- 106

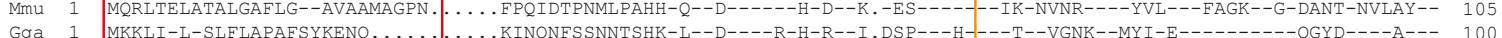
Dre 1 MMKQCARRQMTEPVFRVAVLLALCSLSI GVDVHQAQKTPSISSAALQ-H--D-K-DKLYAY--TRPK-P-EKI---ENTFFSSSTRYILK-DG-KDK-G-T.D----VVLAK 111 GaC 1 MARLL-WT-GI-AIMSVALAVAVDFVLPVAEGHH. EIVKKT

EC2 89 LDREKKSEYHLMALLVDKKTAKTLEHPSNFVIRVIDINDNAPQFTQKAFNGSVNEMSDRGTFVTKVTAVDNDDPTIGGNAEVTYKIIQGQEYFTIDNIG...TIYTAVSNLD 197 $107---$ NI-----T-VI---D-GEN--T--S-T-K-H-VNDNW-V--HRL--A-P-S-AV--S-IS-----A----V-DH-S-M-Q-LK-K---A---S-...R-I-ITKS-- 215 $106----V---F-T--I---N-N K N--Q--S-T V K-H----W-V F S H Q V--A-P-M-A I--S-I R-----A----V A-H-T-L-Q-V K-N---S---S-\ldots$ L-F-KIK--- 214 $101----K A--E-T-H I I-R R N N R S--P--K-I-K-S----A-I-V--I----P-M-R L--S-T K---E-A----V A-H-T---Q--K-N----V-D S-R . G V-S--R A D--\quad 211$ 112 ----TQSV-N-S-S-LNIH-GELVDKDES---V-L-----I-V-DS.DQS--IS-S-RA--TIMK-K-T-A--SSTE.-GRIDFKLIN-TDL-KIKPN...GDLIALK-D-- 218 110 ----NSM-K-T-KMFDGN.GELI-DSGD--VQ-T----I-V-PR.TYN--IM-R-PI--E-VE-K-T-A--N-TA.-GDLR-SLT-REDFAAF-IDSIKGV-SSRTNT-- 218 198 REQRDTYEVVVEARDSPGQNMYMSSTATVIINLIDINDNFPTFTESKYFK..........FDVPETLKVGGEVGRTKVEDIDEPQNRNTKYSFLKERFQEIFAVTTNVNTNEG 300 216 -

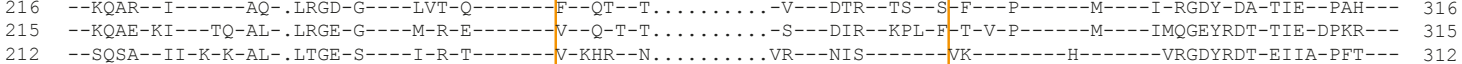
212 . 328

317 -IKPMK-----YIQ--SFIVATDPLIDLRVAKQTRPKS ITNVI INVLDVDEPPVFSKPFYKFE ISEDSKLNNI IGEVSAKDPDAANRNIRYSMR.. NFKDEPIKVTNNGNI 410 316 -IKPTKS----VIQ--TFY------T-RYEYLSS-SG-NKAM-T---------QRHF-H-KLP-NQK.KPL--T-V-----K-Q-S-G--I-KTSDRGQFFRI-KQ-N- 426 313 -IRP-----F-K-AE-RF------HNVNPAYY-PGGSR--STIT-EVT-------T-LS-E-KVR-NDPEIKTL-S-W-H-----K-K--FAR-RASPNGDYVR-SDS-I- 424

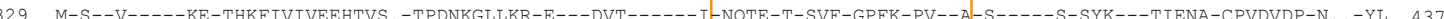




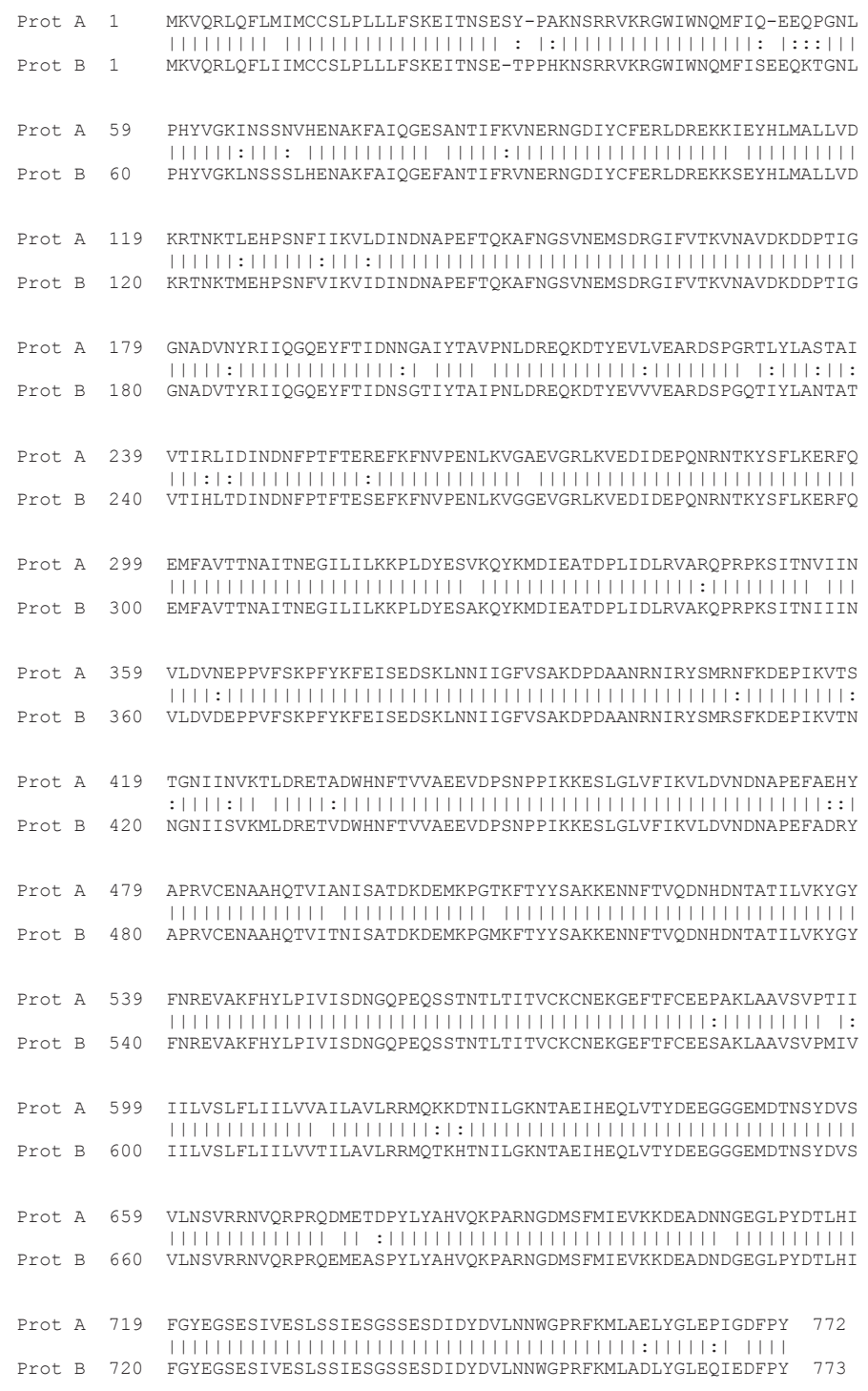

Xenopus laevis and analyzed the temporal and spatial expression of cdh5 during Xenopus embryogenesis.

\section{Cloning of Xenopus laevis cadherin-5}

Surprisingly no Xenopus laevis sequences, which are orthologs to cadherin-5, could be found in cDNA-based sequence databases. We used the cdh5 sequence of Xenopus tropicalis to design a number of different primer pairs covering the entire open reading frame to clone the Xenopus laevis cDNA. Using these primer combinations on NF stage 36 Xenopus laevis cDNA, we were able to clone a 1,9 kb cDNA fragment containing a continuous reading frame of 634 aa. Despite several efforts, we were not able to clone the 5'- and 3'-part of the $x /$-cdh5 cDNA.

To obtain the potential full open reading frame we made use of the recently released genomic sequences of Xenopus laevis. Xenopus laevis contains two genes for cdh5 of which one is identical to our cloned cDNA. Short extensions of the 5'- and 3'end allowed to deduce a full length putative cadherin 5 protein, which showed all the typical characteristics of a type 2 cadherin e.g., a signal peptide, five internal homologous repeats (EC1 to

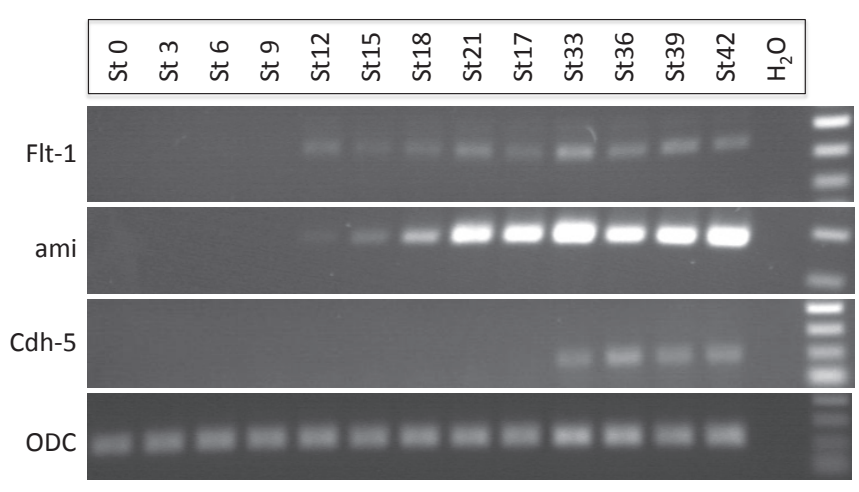

Fig. 2 (Left). Alignment of the putative amino acid sequence from both cadherin-5 paralogs. Both sequences are highly conserved, showing $97.5 \%$ similarity.

Fig. 3 (Right). Temporal analyses of cadherin-5 expression. Expression of $\mathrm{xl}$ cdh5 mRNA was compared to the expression of early vasculogenesis marker genes flt1 andami by semi quantitative rt-PCR. Expression of flt1 and ami could be detected already at low levels at NF stage 12, whereas expression of cdh5 was not detectable before stage 27, demonstrating thatcdh5 expression in Xenopus is restricted to later stages of vessel formation. To exclude false results from genomic DNA contamination we used intron spanning primer pairs. ODC1 was used to control the amount of input RNA.

EC5), a transmembrane domain, a cytoplasmic domain, four conserved cysteine residues, three putative calcium binding motifs (DxNDNxP), and three four-amino acid repeats of unknown function (LDRE) (Vestweber, 2008). Comparison of the deduced amino acid sequence of the Xenopus laevis cDNA with cdh5 sequences of Xenopus tropicalis showed that both sequences are $88,6 \%$ identical and $94 \%$ similar to each other (Fig.1a). Xenopus laevis cdh5 was highly homologues to all other vertebrate cadherin-5 proteins included in this analysis. Highest homology was found with the cdh5 sequence of Gallus gallus (52,5\%) and lowest homology was found with Danio rerio cadherin- 5 sequence (36,2\%/) (Fig.1b). Since two paralogous sequences are contained in the Xenopu laevis genome, we compared the putative amino acid sequnces of both paralogs. Both putative proteins are highly conserved sharing $97.5 \%$ similaritiy, suggesting that both genes might be expressed and have a highly similar function.

\section{Temporal expression of cadherin-5 during Xenopus develop- ment}

To analyze the temporal expression of cdh5 during embryogenesis we prepared cDNA from mRNA collected from a series of Xenopus embryos at different developmental stages. To evaluate the onset of $c d h 5$ expression in the process of vasculogenesis we compared the expression pattern of $c d h 5$ with the expression of ami and flt-1, which are already expressed at the early stages of vascular endothelial cell differentiation (Inui and Asashima, 2006) (Fong et al., 1996). Our rt-PCR analysis showed that earliest ami and flt-1 expression could be detected in late gastrula stage embryos at NF st 12 whereas cdh5 expression could not be detected before the embryos reached tailbud stages (Fig.2). To analyze the expression of the two different genomic loci we designed two 


\section{A}

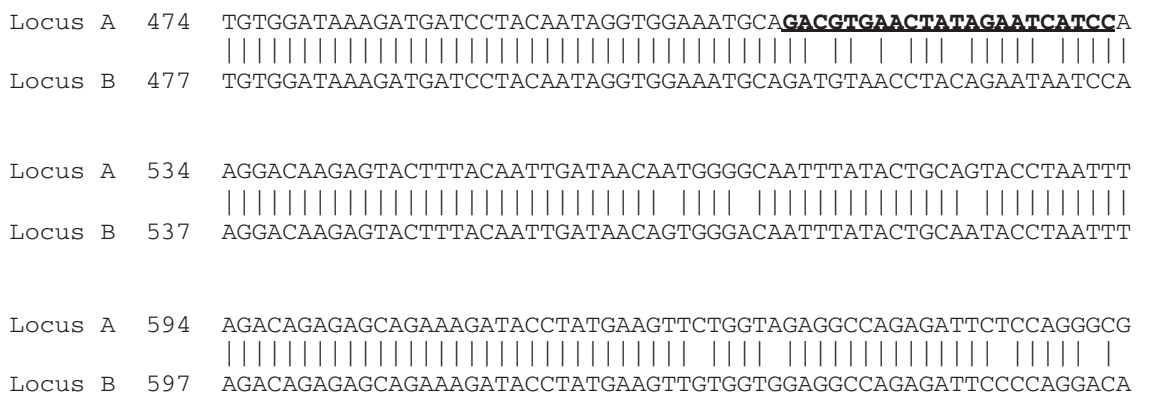

Locus A 654 AACTCTTTACTTGGCAAGCACAGCCATAGTGACCATTCGCTTGATAGACATTAATGACAA || ||||| |||||| ||||||||| ||| |||||| | |||||| || || ||||||||||||| || Locus B 657 AACCATTTACCTGGCAAACACAGCCACAGTAACCATCCACTTGACAGACATTAATGACAA

B

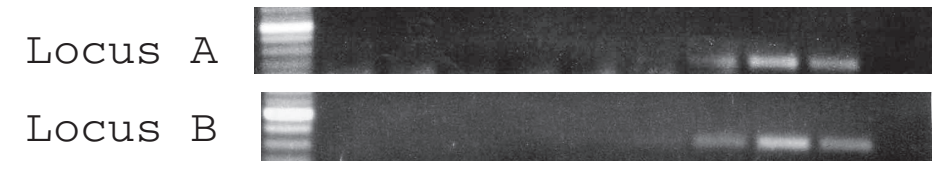

Fig. 4. Comparison of the temporal expression of the two cadherin-5 paralogs. Two primerpairs, specific for either locus A or locus B were used to 536 compare the temporal expression of both paralogs. In figure 4a a part of the nucleotide sequence is shown, demonstrating the high degree of sequence conservation on the nucleotide level. Sequences used for primer pair $A$ are marked in bold letters. $<$ semi-quantitative rt-PCR in figure $4 b$ shows that transcripts from both paralogs could be detected 653 as early as st 27.

656 structures that are subsequently formed e.g.: the anterior aorta, the vessels of the branchial 713 arches, the duct of cuvier, the retinal vein, the heart and the intersomitic veins (Fig. 3). 716 Analysis of sectioned embryos demonstrated that expression of cdh5 expression is strictly restricted to endothelial cells and could not be detected in surrounding tissues (e. g. the myocardial wall in the heart) (Fig. 4).

In this report we describe the cloning and primer pairs that are specific for only one of the two loci (A or B) and used them for rt-PCR on RNA from different developmental stages. Expression of both loci could be detected as early as st 30 and showed an identical temporal pattern. The identity of the PCR products was confirmed by sequence analysis.

\section{Spatialexpression of cadherin-5 during Xenopus development}

Spatial expression of cdh5 was analyzed by in situ hybridization on whole-mount and sectioned early Xenopus embryos. Transcripts were first detectable at NF stage 29/30 in the ventrolateral region, where the first vitelline veins form and in vessels around the developing eye. (Fig. 3). A few hours later at NF st 31 additional expression could be detected in the posterior cardinal vein, which starts to form at this stage of development. In swimming tadpoles at NF st. $36 \mathrm{cdh} 5$ becomes expressed in all vascular the expression pattern of Xenopus laevis cdh5. The high degree of sequence similarity to other vertebrate cdh5 proteins in combination with the described spatial expression pattern strongly suggests that the cadherin gene we identified, is the cdh5 ortholog of Xenopus laevis. Since the genome of Xenopus laevis contains two highly conserved paralogs of $c d h$ we analyzed the temporal expression of both paralogs and could show that both genes are expressed in an identical temporal pattern. However, it is possible that the spatial expression patterns of the two paralogs are different. Unfortunately, impossible to distinguish the potentially different spatial expression of both paralogs by in situ hybridization.

Interestingly, in mice and zebrafish the onset of flt-1 expression, as an early marker of vasculogenesis and cdh5 expression, as a marker for differentiated vascular cells, coincides with the early due to the high degree of nucleotide sequence conservation it is
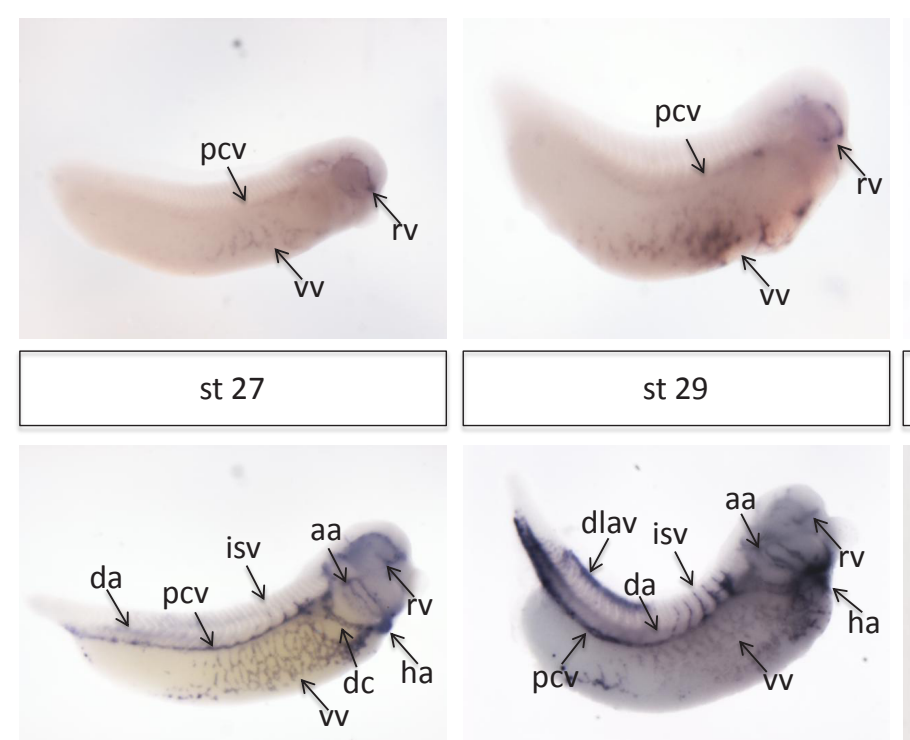

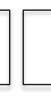
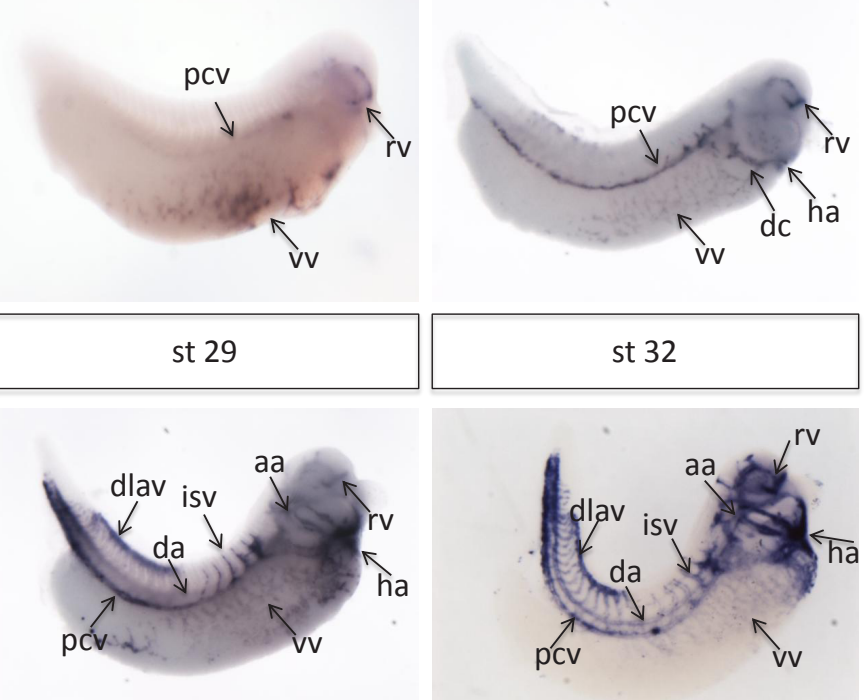

st $33 / 34$ st $35 / 36$

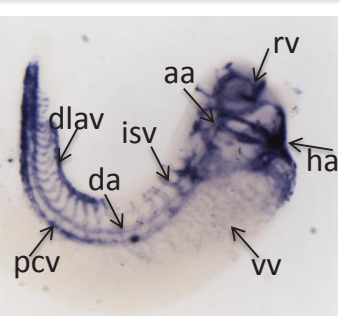

St 37
Fig. 5. Spatial analyses of cadherin-5 expression. Whole-mount in situ hybridization of wild type embryos at developmental stages 27 to 37. Earliest cdh5 expression was detectable at NF stage 27 when first vascular structures developed. Subsequently cdh5 expression could be detected in all newly formed vascular structures. The tissue of a NFstage 37 embryo was cleared before pictures were taken. Abbreviations: (aa) aortic arches, (da) dorsal aorta, (dc) duct of cuvier, (dlav) dorsal longitudinal anastomosing vessel, (ha) heart anlage, (isv) intersomitic veins, (pcv) posterior cardinal vein, (rv) retinal vein, $(v v)$ vitelline veins. 
appearance of blood islands or mesodermal precursors of the vascular system, whereas in Xenopus cdh5 expression was detectable solely much later in clearly formed vascular structures. This could allow an easier dissection of the developmental program leading from early vascular progenitor cells to differentiated endothelial cells forming functional blood vessels in Xenopus.

\section{Materials and Methods}

\section{Animals}

Pigmented and albino Xenopus laevis were obtained from Nasco (Ft. Atkinson, WI). Production and rearing of embryos was as described (Hollemann and Pieler, 1999). Staging of embryos was done according to Nieuwkoop and Faber (1967).

\section{Whole mount in situ hybridization}

In general, whole-mount in situ hybridization was carried out as described (Hollemann et al., 1998). To generate antisense RNA probes, corresponding plasmids were digested and transcribed as follows: cadherin-5, Sall and T7. For the analysis of cadherin-5 expression on sectioned embryos whole mount ISH embryos were embedded in technovit (Kulzer) and $10 \mu \mathrm{m}$ section were made using a microtome (Leica, Germany) and mounted on glass slides.

\section{RNA preparation and reverse transcription}

RNA was prepared from whole Xenopusembryos using a Qiagen RNeasy Kit following the instructions provided by the manufacturers. First strand cDNA was prepared from $500 \mathrm{ng}$ total RNA using oligo-dT- or random primer and reverse transcriptase (Gibco).

\section{$R T-P C R$}

RT-PCR was performed with the following intron spanning primers and PCR-Cycles:

$$
\begin{array}{ll}
\text { XL-ODC1-F } & \text { 5-GCCATTGTGAAGACTCTCTCCATTC, } \\
\text { XL-ODC1R } & \text { 5-TTCGGGTGATTCCTTGCCAC, } 26
\end{array}
$$

Cycles;

$\begin{array}{ll}\text { XL-ami-rt-f202 } & \text { 5-TAAATGGGTGCTGAGTGCAG } \\ \text { XL-ami-rt-r577 } & \text { 5-GTTCCGGCGATTACAGACAT; 28 Cy- }\end{array}$
cles

\section{XL-flt1-rt-f433 5-GCCATCTACGAACCAGGTGT}

XL-flt1-rt-r770 5-AAATGTGGGATTGGGAATGA; 28

Cycles

\section{XT-ve-cadherin-Ex10 5-ATTCTGTGAGGAGGCTGGAA}

XT-ve-cadherin-Ex11 5-CGCCTTCCTCATCATAGGTG; 28 Cycles

XL-cdh5-locusA-550-forw 5-GACGTGAACTATAGAATCATCC

XL-cdh5-locusA-735-rev 5-CAAGCGAATGGTCACTATGG; 34

Cycles

$$
\begin{array}{ll}
\text { XL-cdh5-locusB-689-forw } & \text { 5-CAGGACAAACCATTTACCTG } \\
\text { XL-cdh5-locusB-935-rev } & \text { 5-AGTGATCGCATTTGTGGTAAC; } 30
\end{array}
$$
Cycles

\section{Acknowledgements}

We thank Juliane Herfurth for excellent technical assistance. The work was supported by a grant from the Deutsche Forschungsgemeinschaft to T.H. (HO 1879/3-3).

\section{References}

BREIER, G., BREVIARIO, F., CAVEDA, L., BERTHIER, R., SCHNURCH, H., GOTSCH, U., VESTWEBER, D., RISAU, W. and DEJANA, E. (1996). Molecular cloning and expression of murine vascular endothelial-cadherin in early stage development of cardiovascular system. Blood 87: 630-641.

CLEAVER, O., TONISSEN, K.F., SAHA, M.S. and KRIEG, P.A. (1997). Neovascu-
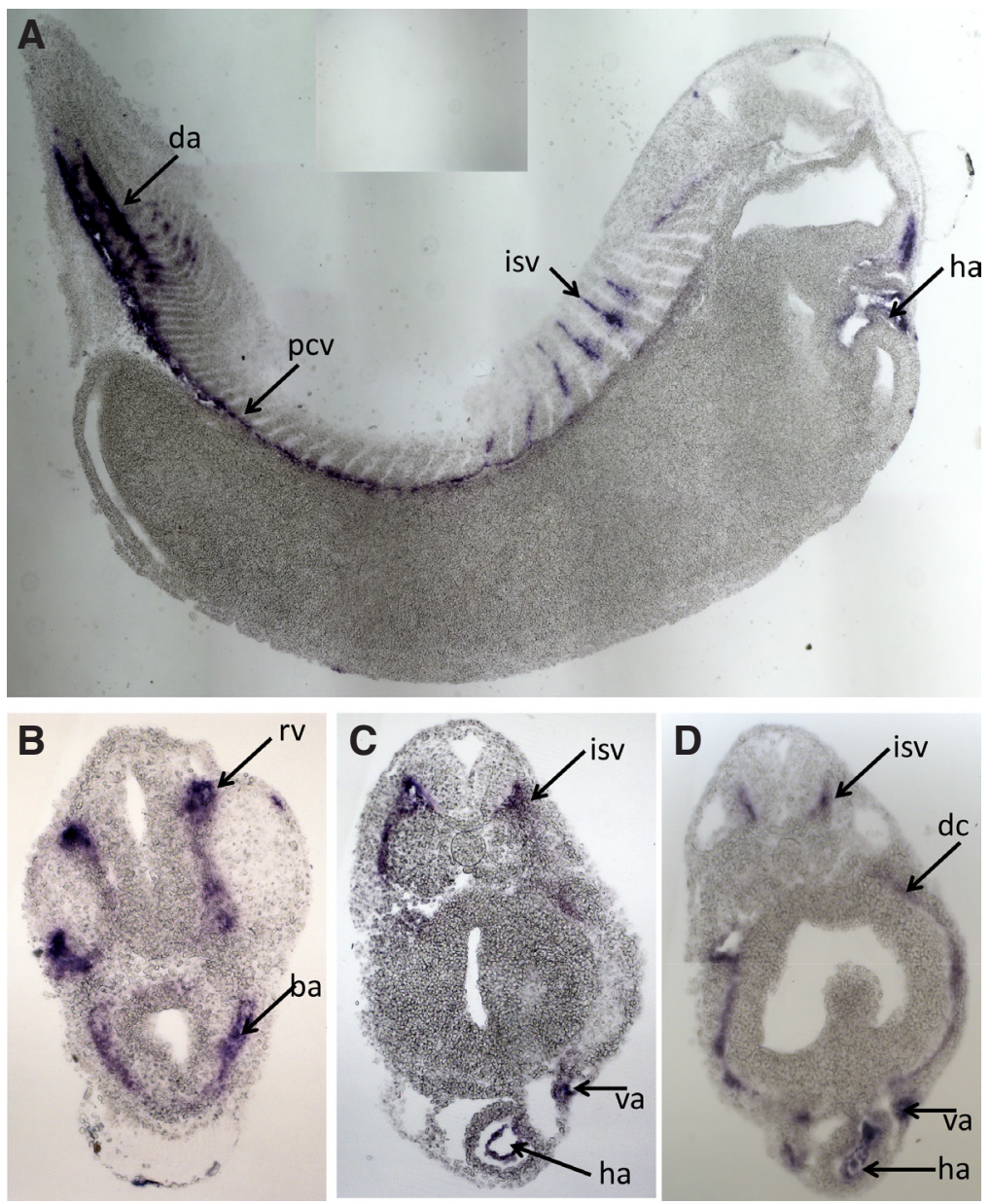

Fig. 6. Spatial analyses of cadherin-5 expression on sectioned embryos. Sagittal section (A) and coronary sections at different positions of st 36 embryos (B,C,D) show, that cdh5 expression is restricted to the endothelial linings of the developing vascular structures. Abbreviations: (aa) aortic arches, (ba) branchial arch, (da) dorsal aorta, (dc) duct of cuvier, (ha) heart anlage, (isv) intersomitic veins, (pcv) posterior cardinal vein, (rv) retinal vein, (va) ventral aorta, (vv) vitelline veins.

larization of the Xenopus embryo. Dev Dyn 210: 66-77.

DUMONT, D.J., FONG, G.H., PURI, M.C., GRADWOHL, G., ALITALO, K. and BREITMAN, M.L. (1995). Vascularization of the mouse embryo: a study of flk-1, tek, tie, and vascular endothelial growth factor expression during development. Dev Dyn 203: 80-92.

FLAMME I., BREIER, G. and RISAU, W. (1995). Vascular endothelial growth factor (VEGF) and VEGF receptor 2 (flk-1) are expressed during vasculogenesis and vascular differentiation in the quail embryo. Dev Biol 169: 699-712.

FONG, G.H., KLINGENSMITH, J., WOOD, C.R., ROSSANT, J. and BREITMAN, M.L. (1996). Regulation of flt-1 expression during mouse embryogenesis suggests a role in the establishment of vascular endothelium. Dev Dyn 207: 1-10.

FONG, G.H., ROSSANT, J., GERTSENSTEIN, M. and BREITMAN, M.L. (1995) Role of the Flt-1 receptor tyrosine kinase in regulating the assembly of vascular endothelium. Nature 376: 66-70.

GORY-FAURE, S., PRANDINI, M.H., POINTU, H., ROULLOT, V., PIGNOT-PAINTRAND, I., VERNET, M. and HUBER, P. (1999). Role of vascular endothelial-cadherin in vascular morphogenesis. Development 126: 2093-2102.

HOLLEMANN, T., CHENY., GRUNZ, H. and PIELER, T. (1998). Regionalized metabolic activity establishes boundaries of retinoic acid signalling. EMBO J17: 7361-1772.

HOLLEMANN, T. and PIELER, T. (1999). Xpitx-1: a homeobox gene expressed during pituitary and cement gland formation of Xenopus embryos. Mech Dev88: 249-252.

HOLMES, K., ROBERTS, O.L., THOMAS, A.M. and CROSS, M.J. (2007). Vascular 


\section{H. Neuhaus et al.}

endothelial growth factor receptor-2: structure, function, intracellular signalling and therapeutic inhibition. Cell Signal 19: 2003-2012.

HOUSER, J.W., ACKERMAN, G.A. and KNOUFF, R.A. (1961). Vasculogenesis and erythropoiesis in the living yolk sac of the chick embryo. A phase microscopic study. Anat Rec 140: 29-43.

INUI, M. and ASASHIMA, M. (2006). A novel gene, Ami is expressed in vascular tissue in Xenopus laevis. Gene Expr Patterns 6: 613-619.

LARSON, J.D., WADMAN, S.A., CHEN, E., KERLEY, L., CLARK, K.J., EIDE, M., LIPPERT, S., NASEVICIUS A., EKKER, S.C., HACKETT, P.B. and ESSNER, J.J. (2004). Expression of VE-cadherin in zebrafish embryos: a new tool to evaluate vascular development. Dev Dyn 231: 204-213.

MITCHELL, I.C., BROWN, T.S., TERADA, L.S., ARMATRUDA, J.F. and NWARIAKU, F.E. (2010). Effect of vascular cadherin knockdown on zebrafish vasculature during development. PLoS One 5: e8807.

NEUHAUS, H., MULLER F. and HOLLEMANN, T. (2010). Xenopus er71 is involved in vascular development. Dev Dyn 239: 3436-3445.
PARDANAUD, L., LUTON, D., PRIGENT, M., BOURCHEIX, L.M., CATALA, M. and DIETERLEN-LIEVRE, F. (1996). Two distinct endothelial lineages in ontogeny, one of them related to hemopoiesis. Development 122: 1363-1371.

RISAU, W. (1995). Differentiation of endothelium. FASEB J 9: 926-933.

SALANGA, M.C., MEADOWS, S.M., MYERS, C.T. and KRIEG, P.A. (2010). ETS family protein ETV2 is required for initiation of the endothelial lineage but not the hematopoietic lineage in the Xenopus embryo. Dev Dyn 239: 1178-1187.

TURPEN, J.B., KELLEY, C.M., MEAD, P.E. and ZON, L.I. (1997). Bipotential primitivedefinitive hematopoietic progenitors in the vertebrate embryo. Immunity 7:325-334

VESTWEBER, D. (2008). VE-cadherin: the major endothelial adhesion molecule controlling cellular junctions and blood vessel formation. Arterioscler Thromb Vasc Biol 28: 223-232.

YAMAGUCHI, T.P., DUMONT, D.J., CONLON, R.A., BREITMAN, M.L. and ROSSANT, J. (1993). flk-1, an flt-related receptor tyrosine kinase is an early marker for endothelial cell precursors. Development 118: 489-498. 


\section{Further Related Reading, published previously in the Int. J. Dev. Biol.}

The role of angiogenic growth factors in organogenesis

Enrico Crivellato

Int. J. Dev. Biol. (2011) 55: 365-375

http://dx.doi.org/10.1387/ijdb.103214ec

Building the vertebrate heart - an evolutionary approach to cardiac development José M. Pérez-Pomares, Juan M. González-Rosa and Ramón Muñoz-Chápuli

Int. J. Dev. Biol. (2009) 53: 1427-1443

http://dx.doi.org/10.1387/ijdb.072409jp

Embryonic development of the proepicardium and coronary vessels

Anna Ratajska, Elzbieta Czarnowska and Bogdan Ciszek

Int. J. Dev. Biol. (2008) 52: 229-236

http://dx.doi.org/10.1387/ijdb.072340ar

Blood vessel/epicardial substance (bves) expression, essential for embryonic development, is down regulated by Grk/EFGR signalling Shengyin Lin, Debiao Zhao and Mary Bownes

Int. J. Dev. Biol. (2007) 51: 37-44

http://dx.doi.org/10.1387/ijdb.052108sl

Pathways in blood and vessel development revealed through zebrafish genetics

Philip S Crosier, Maggie L Kalev-Zylinska, Christopher J Hall, Maria Vega C Flores, Julia A Horsfield and Kathryn E Crosier

Int. J. Dev. Biol. (2002) 46: 493-502

http://dx.doi.org/10.1387/ijdb.12141436

Ets-1 and Ets-2 proto-oncogenes exhibit differential and restricted expression patterns during Xenopus laevis oogenesis and embryogenesis

D Meyer, M Durliat, F Senan, M Wolff, M Andre, J Hourdry and P Remy

Int. J. Dev. Biol. (1997) 41: 607-620

http://dx.doi.org/10.1387/ijdb.9303349

Whole-mount in situ hybridization reveals the expression of the XI-Fli gene in several lineages of migrating cells in Xenopus embryos

D Meyer, P Stiegler, C Hindelang, A M Mager and P Remy

Int. J. Dev. Biol. (1995) 39: 909-919

http://dx.doi.org/10.1387/ijdb.8901193

$$
5 \text { yr ISI Impact Factor }(2011)=2.959
$$
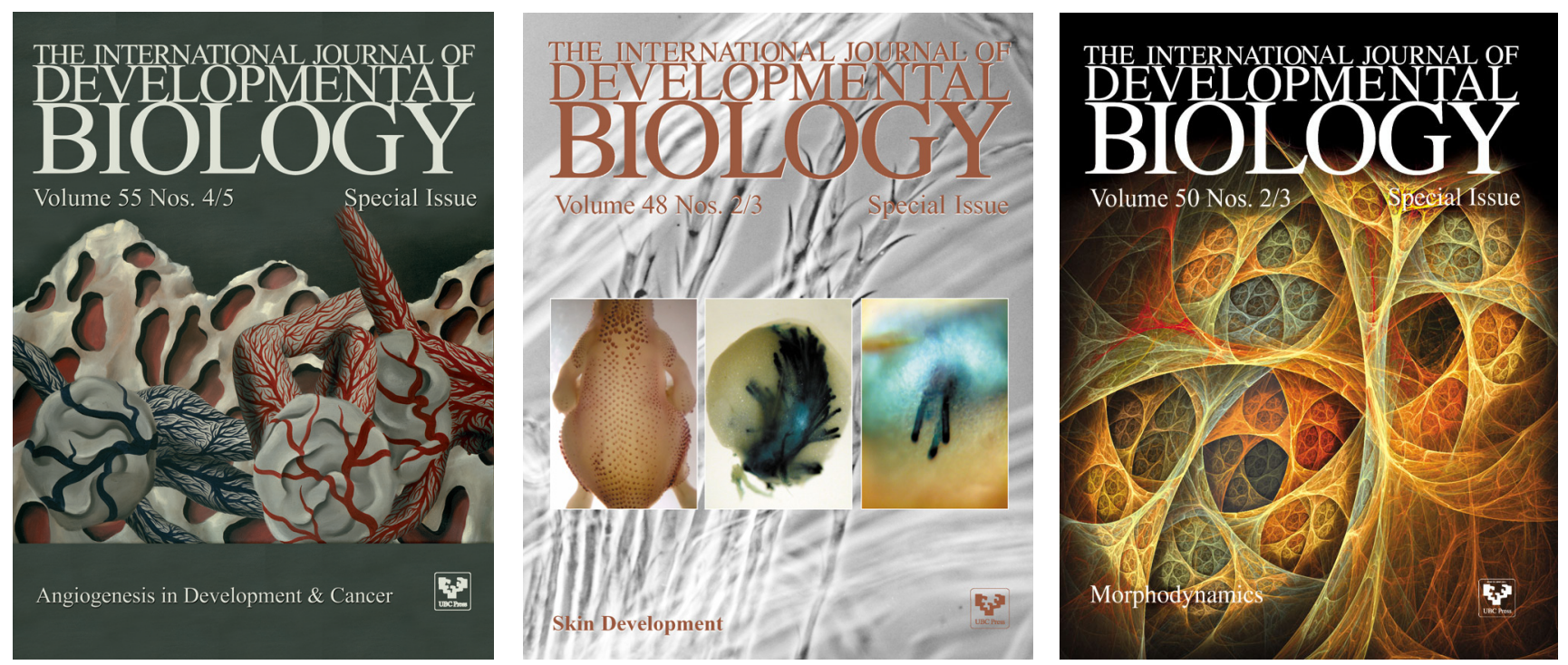